\title{
Policies and programs for the prevention of gastrointestinal cancers in Iran: a document analysis
}

Neda Kabiri

Tabriz University of Medical Sciences

Rahim Khodayari-zarnaq

Tabriz University of Medical Sciences

Manouchehr Khoshbaten

Tabriz University of Medical Sciences

Ali Jannati ( $\sim$ janati1382@gmail.com )

Tabriz University of Medical ScienceS

Research article

Keywords: Document analysis, Gastrointestinal cancer, Health policy analysis, Iran, Prevention

Posted Date: July 3rd, 2019

DOI: https://doi.org/10.21203/rs.2.10934/v1

License: (a) (i) This work is licensed under a Creative Commons Attribution 4.0 International License.

Read Full License 


\section{Abstract}

Background Considering the importance of gastrointestinal cancers and their high prevalence in Iran, the analysis of national and local programs and policies are of high importance. The current document review was conducted to assess policies and programs related to the prevention of colon, stomach, liver, esophageal and pancreas cancers in Iran. Methods This paper used 'policy triangle' as a framework to analyze documents related to gastrointestinal cancer prevention in Iran. We searched PubMed and SCOPUS, as well as web pages of Ministry of Health and Medical Education (MOHME), all Medical Sciences Universities, and some related research centers. Documents were analyzed using MAXQDA 10 software. Results Three documents, one guideline, 16 national meeting reports, and 11 articles were found containing or describing interventions directed at the prevention of gastrointestinal cancers in Iran. Also, a large amount of news was obtained from the searched web pages. Findings of this paper are organized based on the four aspects of health policy triangle including content, context, process, and actors. Health affairs of MOHME developed a plan, called 'Iran Package of Essential Non-communicable Disease' (IraPEN), for preventing three common cancers namely colorectal, breast, and cervix in 2015 . The contextual factors affecting prevalence and incidence of gastrointestinal cancers in this country included economic, social, and cultural. Regarding high prevalence and incidence of gastrointestinal cancers in Iran, prevention programs have been developed in this country since 2012 and have been implemented in some areas. However, these programs don't have any evaluation phase within them. The most effective actor in preventing these cancers in Iran is MOHME. Conclusions Considering the interventions conducted to prevent gastrointestinal cancers in the country, the prevalence and incidence of these cancers have not been diminished. This issue needs care of policy makers in health and other sectors to design and implement policies and strategies in order to prevent these cancers at the primary level. Also, nongovernmental organizations might be attracted to provide financial support.

\section{Background}

Nowadays, there is a big shift from communicable, infectious, childhood and maternal diseases burden to Non-Communicable Diseases (NCDs) in the world. Also, most people spend the last years of their life with disability from chronic diseases (1). Burden of gastrointestinal cancers, as one of the most important NCDs, is predicted to increase in Asia (2). Similarly, trends for the incidence of digestive system cancers, especially for stomach, colorectal, esophageal, and liver cancers in Iran, are increasing. Likewise, total number of Disability Adjusted Life Years )DALYs) and deaths due to these cancers are uprising (3).

In comparison with the Middle East and North African countries, Iran has the highest burden of stomach and esophagus cancers (4). Results from the global burden of diseases in 2015 showed that stomach cancer was ranked the second in Iran for the age- standardized incidence rate (5). The results of this study indicated that mortality rate of stomach cancer in Iran for both males and females decreased from 1990 to 2010, this was not significant when compared to other countries such as China and Japan, though. Besides, age- standardized mortality rate from liver cancer in Iran significantly increased over this time. These two examples might be considered as a warning for Iranian health policy-makers and health 
care providers to design interventions and policies to tackle these fatal conditions and their risk factors (6).

Changes in individuals' lifestyle, socioeconomic conditions, and increasing life expectancy seem to be associated with the current trend of these cancers (7). A recent study indicated that alcohol consumption and tobacco use are important risk factors of esophagus and gastric cancers (8). Also, changes in lifestyle and nutrition, urbanization, and some other metabolic abnormalities such as diabetes, obesity, hypertension, and dyslipidemia have been recognized as risk factors for NCDs in Iran (9).

Recently, there have been some programs developed at national (10) and local (11) levels for the prevention and control of NCDs as a whole. Also, health affairs of Ministry of Health and Medical Education (MOHME) developed a national plan for health transformation, which as a whole includes some programs for the prevention of cancers as a whole (12).

Considering the importance of gastrointestinal cancers and their high prevalence in Iran, the analysis of national and local programs and policies are of high importance. Hence, this document review was conducted to assess and analyze the policies and programs related to the prevention of different types of cancers including colon, stomach, liver, esophageal and pancreas in Iran. Health policy makers and care providers may use the results of this document review in order to design interventions to reduce the prevalence of these cancers.

\section{Methods}

This document review was conducted to assess the policies and programs related to the prevention of common digestive cancers including colon, stomach, liver, esophageal, and pancreas in Iran. The study adopts Walt and Gilson (13) policy triangle approach, which focuses on content, context, process, and actors (Figure 1).

- Content: refers to details of the policy and its constituting parts;

- Context: refers to political, economic, and social factors that may influence health policy;

- Process: refers to the way in which policies are initiated, developed, negotiated, implemented, and evaluated;

- Actors: refer to the individuals, organizations, and governments who influence the policy (14).

Figure 1. Policy analysis triangle, Walt and Gilson (1994) (13)

Search Strategy

A comprehensive search, with no time limit, was conducted on the policies related to the prevention of gastrointestinal cancers. The search engine used was Google. In addition to it, the available documents on the web pages of MOHME, all medical sciences universities, and their concerning research centers, 
which were related to gastrointestinal cancers in Iran, were searched. Also, web page of Salamat News newspaper was searched for any related news about the prevention of gastrointestinal cancers. Minutes and meeting agendas for 'supreme council for health and food security' and 'non- communicable diseases committee of ministry of health' were also manually searched and retrieved. The keywords used in the search for the pertinent documents were: gastrointestinal cancer, colon cancer, stomach cancer, liver cancer, esophageal cancer, and pancreas cancer, along with the terms prevention and screening. Each of these keywords was used separately in Persian language. We searched PubMed and SCOPUS with the above mentioned keywords in combination with 'Iran' AND 'policy OR program', in order to find any related articles. As the first integrated program of WHO to prevent and control non-communicable diseases was published in 1988, the search in these databases was limited to the studies published between January 1988 and 30 October 2018. As a result, three documents, one guideline, 16 national meeting reports of 'supreme council for health and food security' and 'non- communicable diseases committee of ministry of health', and 11 articles were found containing or describing interventions directed at the prevention of gastrointestinal cancers in Iran. Moreover, a large number of web pages were attained through search.

Analysis of the documents

The documents were organized according to their publication date. Then, after the duplicates were discarded they were analyzed by means of using deductive thematic analysis. The documents were read and re- read for several times. After the researcher was completely indulged in the documents, preliminary coding of documents was presented according to the components of the health policy triangle by one of the researchers (NK). These codes were then committed by the other researchers (AJ, RK, MK). MAXQDA 10 software was used to organize and analyze the data.

\section{Results}

\section{Content}

A program called 'Iran Package of Essential Non-communicable Disease (IraPEN)' for prevention, early diagnosis and screening of three cancers of breast, cervix, and colorectal was developed in 2017. The program is being implemented in some areas of the country $(15,16)$. The interventions defined for colon cancer in this program include three primary, secondary and tertiary levels of care: Fecal Occult Blood Test (FOBT)/ Fecal Immunochemical Test (FIT) test at the primary level, colonoscopy at the secondary level, and surgery at the tertiary level of care.

'National comprehensive program of cancer control' was developed in 2011 by the cancer office of health affairs in MOHME with the aim of reducing death from colorectal cancer. This program has three strategies of identification and early diagnosis, public education, and providing infrastructures for implementing prevention system for colorectal cancer. All the medical sciences universities were obliged to establish these infrustructures to complete this program until the end of the fifth development plan (17). 
Besides, a clinical guideline for the prevention and screening of colorectal cancer was developed in 2015 for family physicians (18).

Analyzing data from web pages and news showed that other methods of colorectal cancer screening include Barium enema, CT colonography, and Sigmoidoscopy. Hepatitis B and fatty liver are the two main factors of liver cancer. In order to prevent liver cancer, national plan of Hepatitis B vaccination has been in place since 2007 in Iran.

Also, review of the document showed that a number of congresses on the prevention of gastrointestinal cancers are organized annually along with training and public informing. It is worth mentioning that analysis of the documents showed that 'dust' is responsible for $75 \%$ of digestive cancers, which requires further study and finding appropriate way. In addition, combating Helicobacter Pylori was shown to be the important factor in reducing gastric cancer.

\section{Context}

Based on the results obtained from review of the documents, the contextual factors affecting prevalence and incidence of gastrointestinal cancers in Iran include economic, social, and cultural.

Financial problems are of the reasons that people seldom visit their doctor for diagnosis and screening of these cancers. Also, economic problems are indirectly related to the risk factors of these cancers such as addiction, and weak oral hygiene.

Social factors include shame and embarrassment of people for screening of these cancers, which per se leads to increase in this type of cancer. Assessing attitudes and beliefs of Iranians towards colorectal cancer screening indicated that self-confidence, intention to screening, perceived susceptibility, cancer worries, response efficacy, and social support were observed to secure poor scores among the population (19).

Cultural factors are mostly related to life style of people. For example, northeastern part of Iran is a high risk area for esophageal cancers due to drinking hot liquids and food preparation methods $(20,21)$.

\section{Process}

Agenda setting

After the results of many studies on the prevalence and incidence of gastrointestinal cancers in Iran were released, IraPEN was developed in 2015, $(7,22-25)$. One of the objectives of this program was to prevent colorectal cancer as this cancer is completely preventable (26). Also, because Northeastern Iran is one of the high incidence areas for esophageal cancer in the world, most of the studies about risk factors of this cancer and their relationship with the cancer prevention in Iran have been done in this area $(20,21,27-$ 30).

Formulation 
Regarding high prevalence and incidence of gastrointestinal cancers, specifically colon cancer, in Iran and the ease of preventing and treating gastrointestinal cancers, clinical guideline for screening colorectal cancer was reviewed and approved in 2012 and IraPEN was developed in 2015. IraPEN was formulated based on the four suggested areas of World Health Organization (WHO) (15).

Implementation

In order to enable health network to respond, implementation of IraPEN was piloted in four districts of Naghadeh, Maragheh, Shahreza, and Baft. All the Interventions for the prevention and early diagnosis of colorectal cancer were conducted in this program. Following the pilot, Medical Sciences Universities in some areas planned to implement IraPEN and had some motivating strategies such as doing free of charge FIT tests and free screening on a specified day.

Training workshops were held for the providers of IraPEN in some universities. In addition, training sessions were held for some target populations on the prevention of these cancers.

Evaluation

Since the national programs for the prevention of gastrointestinal cancers have been newly developed, there hasn't been any evaluation conducted yet, which can be considered as a limitation for such national programs.

\section{Actors}

The main participant in formulating the national plan for the prevention of colorectal cancer through IraPEN was non-communicable diseases management in health affairs of MOHME. Moreover, the participants in formulating comprehensive plan for cancer control included cancer office of MOHME. Also, clinical guideline of colorectal cancer screening was formulated by research center of liver and gastrointestinal diseases of Dr Shariati Hospital of Tehran University of Medical Sciences. The participants in implementing IraPEN in different cities included the Medical Sciences Universities.

\section{Discussion}

The current study was conducted to review documents concerning the prevention of gastrointestinal cancers in Iran. This offers policy makers and health care providers an opportunity to make improvements in the prevention of gastrointestinal cancers not only in Iran, but in other countries with similar problems.

Screening methods of colorectal and liver cancer in national programs were similar to the methods in other studies (31-34). Public education, which is considered as an objective to prevent these cancers, is mentioned in other similar studies $(31,35)$. People as a target population should be informed about advantages of prevention and early diagnosis of gastrointestinal cancers. Lack of awareness among population was a leading cause of low participation in colorectal cancer screening rate in one study (36). 
There is no action for combating Helicobacter Pylori that was mentioned as a prevention way of gastric cancer in national documents. Oral immunization and vaccination against Helicobacter Pylori is considered as therapeutic approaches to Helicobacter induced gastritis in some countries; however, its safety has not been confirmed yet $(37,38)$.

Based on the document review of the present study, economic, social and cultural factors were the most important contextual factors in gastrointestinal cancers in Iran. Socioeconomic differences among population have shown to be a determinant factor on the incidence and mortality from cancers (39). These differences can be reduced by improving educational opportunities, income distribution, healthrelated behavior, or access to health care in the countries (40). Results of a systematic review and metaanalysis showed that gastric cancer was positively associated with the low level of socioeconomic position (41).

The results obtained from this study indicated that out of all gastrointestinal cancers only colorectal cancer is included in national programs. More interesting point is that, there is no evaluation section designed or predicted in these programs. It is recommended that at the initiation of the program the indicators concerning evaluation and also actors responsible for leading the evaluation be defined in such national programs (42).

Review of the document manifested that National programs in Iran are all developed by the MOHME. Direct involvement of people with gastrointestinal cancers is uncommon in developing programs and documents. Also, private sector and Non- Governmental Organization (NGO) engagement is not facilitated in the development of such programs. Involvement of a diverse range of actors in policy development and implementation is beneficial in a way that it may enhance the success of a health policy and intervention (43).

\section{Conclusion}

Although the national plan for the control and prevention of NCDs and colorectal cancer were developed and implemented since 2015 , some other strategies such as national hepatitis B vaccination and informing public were done in the last decades. Considering these interventions, the prevalence and incidence of gastrointestinal cancers have not been diminished. This issue needs care of policy makers in health and other sectors to design and implement policies and strategies in order to prevent these cancers at the primary level. Also, NGOs might be attracted to provide financial support.

\section{List Of Abbreviations:}

NCDs

DALYS

MOHME 
IraPEN

FOBT

FIT

WHO

NGO

\section{Declarations}

Ethical approval

Ethical approval was not required as the documents used in this study were publicly available.

Consent for publication

Not applicable

Availability of data and materials

The datasets used and/or analyzed during the current study are available from the corresponding author on reasonable request.

Competing interests: The authors declare that they have no competing interests.

Funding: This study was part of a PhD dissertation approved and supported financially by Tabriz University of Medical Sciences, Tabriz, Iran. The funding body has no role in the design of the study, nor in collection, analysis, and interpretation of data and in writing the manuscript.

Authors' contributions

NK and AJ contributed to the conception of the study. RK and MK participated in study design. NK searched the web pages and data bases and extracted data from included studies. NK and RK analyzed the data. All authors have read and approved the manuscript.

Acknowledgements

This study was part of a PhD dissertation approved and supported by Tabriz University of Medical Sciences, Tabriz, Iran. The approval code is (IR.TBZMED.REC.1397.618).

\section{References}


1. Sepanlou SG, Malekzadeh F, Naghavi M, Forouzanfar MH, Shahraz S, Moradi-Lakeh M, et al. Trend of Gastrointestinal and Liver Diseases in Iran: Results of the Global Burden of Disease Study, 2010. Middle East J Dig Dis. 2015;7:121-37.

2. Pourhoseingholi MA, Vahedi M, Baghestani AR. Burden of gastrointestinal cancer in Asia; an overview. Gastroenterol Hepatol Bed Bench. 2015;8(1):19-27.

3. Malekzadeh F, Sepanlou SG, Poustchi H, Naghavi M, Forouzanfar MH, Shahraz S, et al. Burden of gastrointestinal and liver diseases in Iran: estimates based on the global burden of disease, injuries, and risk factors study, 2010. Middle East J Dig Dis. 2015;7:138-54.

4. Sepanlou SG, Malekzadeh F, Delavari F, Naghavi M, Forouzanfar MH, Moradi-Lakeh M, et al. Burden of gastrointestinal and liver diseases in Middle East and North Africa: results of global burden of diseases study from 1990 to 2010. Middle East J Dig Dis. 2015;7(4):201-15.

5. Fitzmaurice C. Burden of cancer in the Eastern Mediterranean Region, 2005-2015: findings from the Global Burden of Disease 2015 Study. Int J Public Health. 2017:1-14.

6. Naghavi M, Shahraz S, Sepanlou SG, BESc PN, Pourmalek F, Lozano R, et al. Health Transition in Iran toward Chronic Diseases Based on Results of Global Burden of Disease 2010. Arch Iran Med. 2014;17(5):321-35.

7. Darabi M, Lari MA, Motevalian SA, Motlagh A, Arsang-Jang S, Jaberi MK. Trends in gastrointestinal cancer incidence in Iran, 2001-2010: a joinpoint analysis. Epidemiology and Health. 2016;38.

8. Dong J, Thrift AP. Alcohol, smoking and risk of oesophago-gastric cancer. Best Pract Res Clin Gastroenterol. 2017;31(5):509-17.

9. Esteghamati A, Meysamie A, Khalilzadeh O, Rashidi A, Haghazali M, Asgari F, et al. Third national Surveillance of Risk Factors of Non-Communicable Diseases (SuRFNCD-2007) in Iran: methods and results on prevalence of diabetes, hypertension, obesity, central obesity, and dyslipidemia. BMC Public Health. 2009;9(1):167.

10. Peykari N, Hashemi H, Dinarvand R, Haji-Aghajani M, Malekzadeh R, Sadrolsadat A, et al. National action plan for non-communicable diseases prevention and control in Iran; a response to emerging epidemic. J Diabetes Metab Disord. 2017;16(1):3.

11. Nekouian R, Rasouli BS. Implementation of cancer prevention control program in private sector in Iran. J Cancer Policy. 2017;13:70-4.

12. MOHME. Summery of transformation and function program in health2016.

13. Walt G, Gilson L. Reforming the health sector in developing countries: the central role of policy analysis. Health Policy Plan. 1994;9(4):353-70. 
14. Buse K, Mays N, Walt G. Making health policy: McGraw-Hill Education (UK); 2012.

15. MOHME. Basic interventions for non communicable diseases in Iranian primary health care "IraPEN". 2017.

16. MOHME. Implementation guide and educational concept for the prevention program of colorectal, breast amd uterine cancers. Tehran: Health affairs, non- communicable disease office2017.

17. MOHME. Comprehensive plan for cancer control. In: affairs h, editor:: MOHME; 2011.

18. DDRC. Clinical guideline for screening of colorectal cancer. 2015.

19. Salimzadeh H, Eftekhar H, Delavari A, Malekzadeh R. Psycho-social Determinants of Colorectal Cancer Screening in Iran. Int J Prev Med. 2014;5(2):185-90.

20. Islami F, Pourshams A, Nasrollahzadeh D, Kamangar F, Fahimi S, Shakeri R, et al. Tea drinking habits and oesophageal cancer in a high risk area in northern Iran: population based case-control study. BMJ (Clinical research ed). 2009 26;338:b929.

21. Golozar A, Etemadi A, Kamangar F, Fazeltabar Malekshah A, Islami F, Nasrollahzadeh D, et al. Food preparation methods, drinking water source, and esophageal squamous cell carcinoma in the high-risk area of Golestan, Northeast Iran. Eur J Cancer Prev. 2016;25(2):123-9.

22. Salimzadeh H, Bishehsari F, Sauvaget C, Amani M, Hamzehloo G, Nikfarjam A, et al. Feasibility of Colon Cancer Screening by Fecal Immunochemical Test in Iran. Arch Iran Med. 2017;20(12): 726-733.

23. Besharati F, Karimi-Shahanjarini A, Hazavehei SMM, Bashirian S, Bagheri F, Faradmal J. Development of a colorectal cancer screening intervention for Iranian adults: appling intervention mapping. Asian Pac J Cancer Prev. 2017;18(8):2193-99.

24. Islami F, Kamangar F, Aghcheli K, Fahimi S, Semnani S, Taghavi N, et al. Epidemiologic features of upper gastrointestinal tract cancers in Northeastern Iran. Br J Cancer. 2004;90(7):1402-6.

25. Somi MH, Mirinezhad K, Farhang S, Jazayeri E, Sani A, Seif-Farshad M, et al. Gastrointestinal cancer occurrence in East Azarbaijan: a five year study from North Western Iran. Asian Pac J Cancer Prev. 2006;7(2):309-12.

26. Fatemi S, Moghimi B, Maserrat E, Zali M. Strategy of preventing colorectal cancer in the Iranian population. Journal of Medical Organization of Islamic Republic of Iran. 2010;28(4):444-9.

27. Hashemian M, Poustchi H, Abnet CC, Boffetta P, Dawsey SM, Brennan PJ, et al. Dietary intake of minerals and risk of esophageal squamous cell carcinoma: results from the Golestan Cohort Study. Am J Clin Nutr. 2015;102(1):102-8. 
28. Roshandel G, Khoshnia M, Sotoudeh M, Merat S, Etemadi A, Nickmanesh A, et al. Endoscopic screening for precancerous lesions of the esophagus in a high risk area in Northern Iran. Arch Iran Med. 2014;17(4):246-52.

29. Moossavi S, Mohamadnejad M, Pourshams A, Poustchi H, Islami F, Sharafkhah M, et al. Opium Use and Risk of Pancreatic Cancer: A Prospective Cohort Study. Cancer epidemiology, biomarkers \& prevention. 2018;27(3):268-73.

30. Kamangar F, Malekzadeh R, Dawsey SM, SAEIDI F. Esophageal cancer in Northeastern Iran: a review. Arch Iran Med. 2007;10(1):70-82.

31. Bridges JF, Gallego G, Blauvelt BM. Controlling liver cancer internationally: A qualitative study of clinicians' perceptions of current public policy needs. Health Res Policy Syst. 2011 28;9-32.

32. Buchman S, Rozmovits L, Glazier RH. Equity and practice issues in colorectal cancer screening: Mixed-methods study. Can Fam Physician. 2016;62(4):e186-93.

33. Dawson G, Crane M, Lyons C, Burnham A, Bowman T, Perez D, et al. General practitioners' perceptions of population based bowel screening and their influence on practice: a qualitative study. BMC Fam Pract. 2017;18(1):36.

34. Goel V, Gray R, Chart P, Fitch M, Saibil F, Zdanowicz Y. Perspectives on colorectal cancer screening: A focus group study. Health Expect. 2004;7(1):51-60.

35. Jilcott Pitts SB, Lea CS, May CL, Stowe C, Hamill DJ, Walker KT, et al. "Fault-line of an earthquake": a qualitative examination of barriers and facilitators to colorectal cancer screening in rural, Eastern North Carolina. J Rural Health. 2013;29(1):78-87.

36. Priaulx J, de Koning HJ, de Kok IM, Széles G, McKee MJHP. Identifying the barriers to effective breast, cervical and colorectal cancer screening in thirty one European countries using the Barriers to Effective Screening Tool (BEST). Health Policy. 2018;122(11):1190-7.

37. Corthésy-Theulaz I, Porta N, Glauser M, Saraga E, Vaney A-C, Haas R, et al. Oral immunization with Helicobacter pylori urease $\mathrm{B}$ subunit as a treatment against Helicobacter infection in mice.

Gastroenterology. 1995;109(1):115-21.

38. Blanchard TG, Czinn SJJGC. Current status and prospects for a Helicobacter pylori vaccine. Gastroenterol Clin North Am. 2015;44(3):677-89.

39. Bayo J, Molina R, Pérez J, Pérez-Ruíz E, Aparicio J, Beato C, et al. SEOM clinical guidelines to primary prevention of cancer (2018). Clin Trans/ Oncol. 2019;21(1):106-13.

40. Mackenbach JP, Stirbu I, Roskam AJ, Schaap MM, Menvielle G, Leinsalu M, et al. Socioeconomic inequalities in health in 22 European countries. N Engl J Med. 2008;358(23):2468-81. 
41. Uthman OA, Jadidi E, Moradi T. Socioeconomic position and incidence of gastric cancer: a systematic review and meta-analysis. J Epidemiol Community Health. 2013;67(10):854-60.

42. O'Connell S, Mc Carthy VJC, Savage EJBHSR. Frameworks for self-management support for chronic disease: a cross-country comparative document analysis. BMC Health Serv Res. 2018;18(1):583.

43. Pizzo E, Doyle C, Matthews R, Barlow J. Patient and public involvement: how much do we spend and what are the benefits? Health Expect. 2015;18(6):1918-26.

\section{Figures}

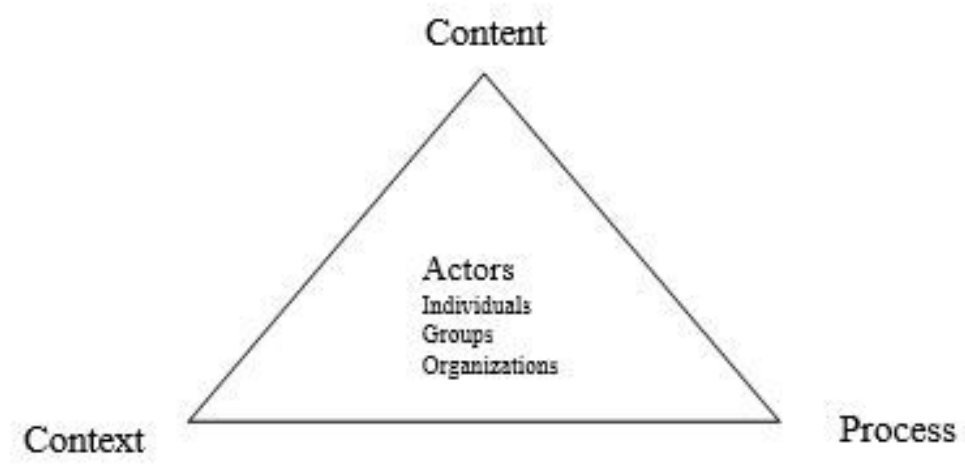

Figure 1

Policy analysis triangle, Walt and Gilson (1994) (13) 